\title{
APPLICATION OF AIRBORNE LIDAR IN RIVER ENVIRONMENTS: THE RIVER COQUET, NORTHUMBERLAND, UK
}

\author{
M. E. CHARLTON, ${ }^{1 *}$ A. R. G. LARGE$^{1}$ AND I. C. FULLER ${ }^{2}$ \\ 1 Department of Geography, University of Newcastle, Newcastle upon Tyne, NE1 7RU, UK \\ 2 Division of Geography, University of Northumbria, Newcastle upon Tyne, NE1 8ST, UK
}

Received 10 July 2001; Revised 12 July 2002; Accepted 1 August 2002

\begin{abstract}
The potential offered by LiDAR (laser-induced direction and ranging) for the mapping of gravel-bed river environments is addressed in this paper. A LiDAR dataset was obtained for a reach of the River Coquet, Northumberland, UK. Topographic data were acquired from the field at the same time using theodolite-EDM survey of a number of cross-profiles across the active river channel and bar units. These cross-profiles provide a means of comparing measurements from the LiDAR data with ground survey. Ordnance Survey large-scale mapping was used to georeference the survey data, which were then integrated with the LiDAR dataset using GIS software. A close correspondence between ground survey-derived cross-profiles and those generated using LiDAR is observed. However, the presence of both vegetation and deep water introduces anomalies in the LiDAR surface. Correction for these anomalies is needed to improve the accuracy of LiDAR mapping in the UK context and similar river environments. It is concluded that LiDAR has potential as an accurate survey tool for obtaining high resolution topographic data from unvegetated, exposed bar surfaces. Copyright $\subset 2003$ John Wiley \& Sons, Ltd.
\end{abstract}

KEY WORDS: LiDAR; river channel; cross-profile; surface quality

\section{INTRODUCTION}

Intensive mapping of river channel topography in large $(>1 \mathrm{~km})$ dynamic reaches using traditional ground survey or analytical (manual) photogrammetry may exert a high demand on operator time and cost, especially when including the survey of morphological detail which is at a scale larger than the gross channel-bar unit. Sub-bar morphology (e.g. chute channels, sediment lobes) may be ignored to rationalize time in the field, or at the photogrammetric plotter; however, these features may represent significant changes in sediment storage within the channel system (Fuller et al., 2002). Whilst digital automated photogrammetry (e.g. Westaway et al., 2000) can be used at a range of spatial scales to overcome some of these deficiencies, airborne LiDAR is a potentially useful development for the acquisition of such terrain data. While differential GPS also has potential for rapid topographic data acquisition (e.g. Brasington et al., 2000), areal extent does remain a limiting factor. LiDAR, on the other hand, permits rapid gathering of topographic data for large areas, up to $90 \mathrm{~km}^{2}$ per hour (Marks and Bates, 2000).

LiDAR, variously termed in the literature as 'laser-induced direction and ranging' (e.g. Marks and Bates, 2000) or 'light detection and ranging' (e.g. Optech, 2001), provides laser-based measurements of the distance between an aircraft carrying the sensor and the ground. The resulting measurements can be post-processed to provide a digital elevation model with a precision within $15 \mathrm{~cm}$ (Fowler, 2000). LiDAR consequently has significant potential for generating a high-resolution digital terrain surface of complex river channel environments incorporating morphological features at a range of scales. Its precision when applied in gravelbed river systems is untested, and this paper evaluates the extent to which LiDAR may be used to provide reliable measurements of topography in such environments.

\footnotetext{
* Correspondence to: M. E. Charlton, Department of Geography, Daysh Building, University of Newcastle, Newcastle upon Tyne,
} NE1 7RU, UK. E-mail: martin.charlton@ncl.ac.uk 
Airborne laser techniques have been widely applied in physical geography (Innes and Koch, 1998; Bissonnette et al., 1997; McHenry et al., 1982; Parson et al., 1997; Irish and White, 1998; Gauldie et al., 1996; Krabill et al., 1995; Wadhams, 1995; Ritchie et al., 1992, 1996). Within geomorphology, the use of airborne laser scanning has focused particularly on the measurement of ephemeral channels and gullies (e.g. Jackson et al., 1988; Ritchie and Jackson, 1989; Ritchie et al., 1994, 1995) and assessment of flood risk (Marks and Bates, 2000).

The integration of LiDAR with airborne GPS facilitates the wider use of high resolution DEMs in physical applications (e.g. Marks and Bates, 2000). The method of survey is rapid, relatively economic, allows survey of difficult terrain, and large areas (for example a river catchment). This would appear to make it an attractive alternative to ground-based survey methods. However, it is difficult to determine the level of precision of LiDAR measurements for any one survey. This feature has been identified by Brinkman and O'Neill (2000), who observe that elevations are generated from three sources: (i) the LiDAR sensor, (ii) the inertial navigation unit (INU) of the aircraft and (iii) GPS. The LiDAR measurements must be corrected for the pitch, roll and yaw of the aircraft, and the GPS information allows the slant distances to be corrected and converted into a measurement of ground elevation relative to the WGS84 datum. The measurements are taken from side to side in a swath as the aircraft flies along its path; those measurements at the centreline of the swath are more precise than those near the edge. Brinkman and O'Neill (2000) also observe that both horizontal and vertical precision depend on the flying height (where horizontal precision is $1 / 2000$ th of the flying height); horizontal precision will thus be 'accurate to 15 centimetres or better' when the flying height is at or below $1200 \mathrm{~m}$ (Brinkman and O'Neill, 2000). In complex topography, small lateral offsets associated with the INU and GPS will be translated into vertical error in the LiDAR surface. This is less of a problem on open, unvegetated surfaces than in areas with tall vegetation cover. If the flight layout can be optimized for GPS (with at least six satellites in view) then precisions of 7-8 $\mathrm{cm}$ are theoretically achievable.

The Environment Agency (EA) has commissioned LiDAR surveys of a number of river and coastal environments. The output from the flights and subsequent data processing is a series of DEMs with densities in the order of 64600 topographic measurements per $\mathrm{km}^{2}$ (Marks and Bates, 2000). This is equivalent to a resolution of $3.9 \mathrm{~m}^{-1}\left(\sqrt{ } 1000000 \mathrm{~m}^{2} / \sqrt{ } 64000\right.$ measurements). Figure 1 depicts a mosaic of two adjacent $1 \mathrm{~km}^{2}$ tiles (nt9502 and nt9602) viewed as an illuminated surface from the southwest. No vertical exaggeration has been applied. As well as showing the undulation of the valley sides, and some faintly visible palaeochannels on the floodplain, vegetation cover is clearly visible. In the study area, white patches indicate where the LiDAR sensor has failed to make a reading. It should be noted that these data gaps are all in the river channel.

Superimposed on Figure 1 is the outline of the area incorporating the study reach on the River Coquet at Holystone (OSGR: NY 958027), located some $25 \mathrm{~km}$ downstream from the river's source in the Cheviot Hills and draining a subcatchment area of some $225 \mathrm{~km}^{2}$ (Figure 2). The contemporary active channel at Holystone is locally divided by expanses of bare gravel, but has well defined pool-riffle units, fitting the criteria for a wandering channel type (Ferguson and Werritty, 1983), and displaying a complex assemblage of channel, bar and sub-bar morphology (Fuller et al., 2002). From historical maps dating back over the past 150 years, the Coquet in this locality is seen to be characterized by a high degree of lateral instability and channel avulsion. Recent calculations show volumes of sediment in excess of $2000 \mathrm{~m}^{3}$ to be reworked on an annual basis within the reach (Fuller et al., 2002). The question remains, however, as to the applicability of LiDAR data in the context of reach-scale topographic mapping of such gravel-bed channel systems. In order to address this, we compare measurements taken from the LiDAR data with spatially corresponding measurements obtained from tachometric survey for a series of cross-sections along the reach.

\section{METHODS}

Post-processed LiDAR data, derived from a single pulse scanning sensor, were obtained by the EA throughout the River Coquet catchment on 19 March 1998. No assessments of precision were available for this data set. The LiDAR measurements were georeferenced using the WGS84 datum used by the NAVSTAR Global Positioning System. Prior to any integration with Ordnance Survey (OS) data, all measurements had to be 


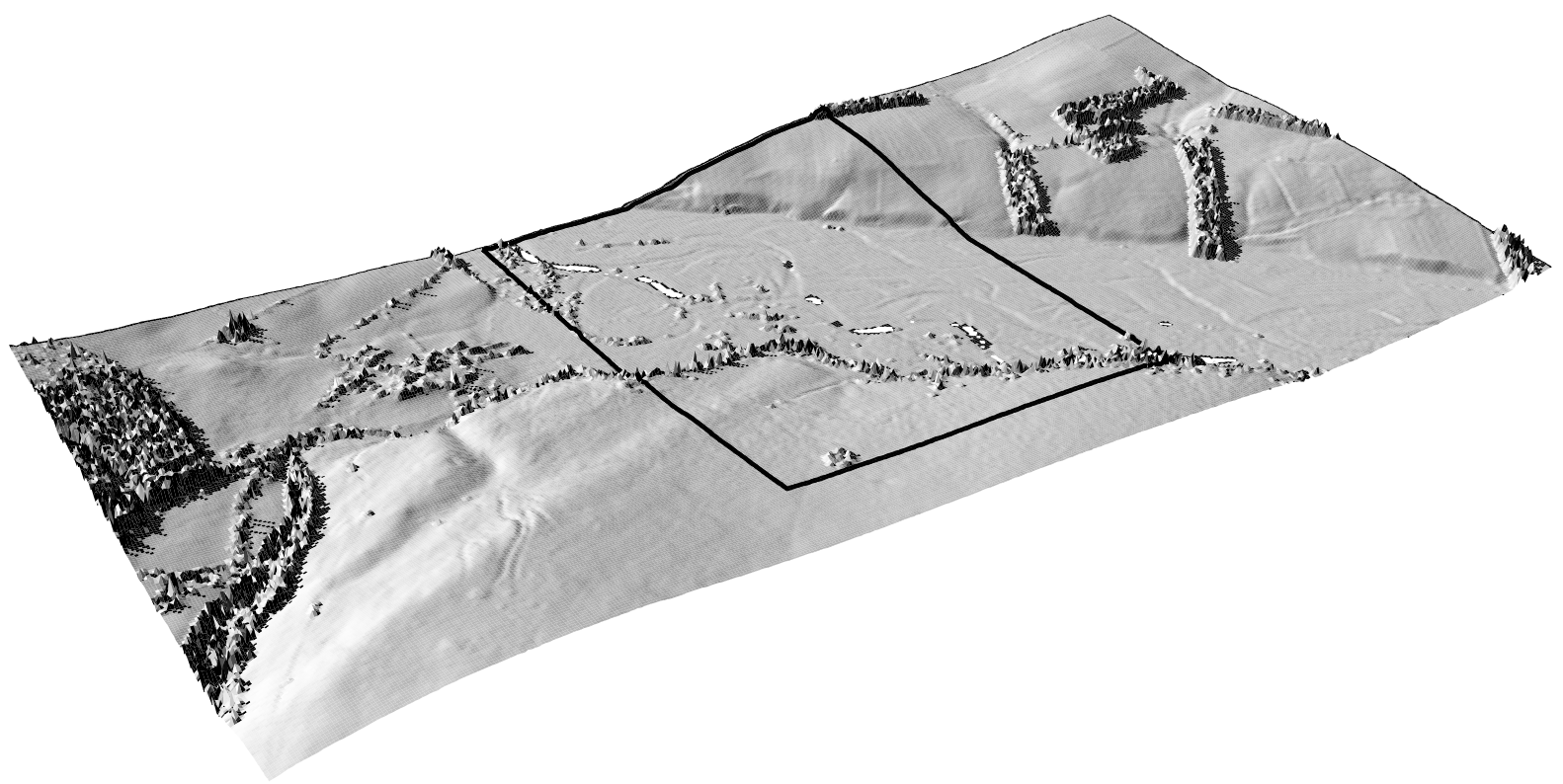

Figure 1. Perspective, viewed from the southwest, of the LiDAR elevation surface of a section of the River Coquet, showing the location of the study reach. The area shown is $2 \mathrm{~km} \times 1 \mathrm{~km}$. Flow is from northwest to southeast

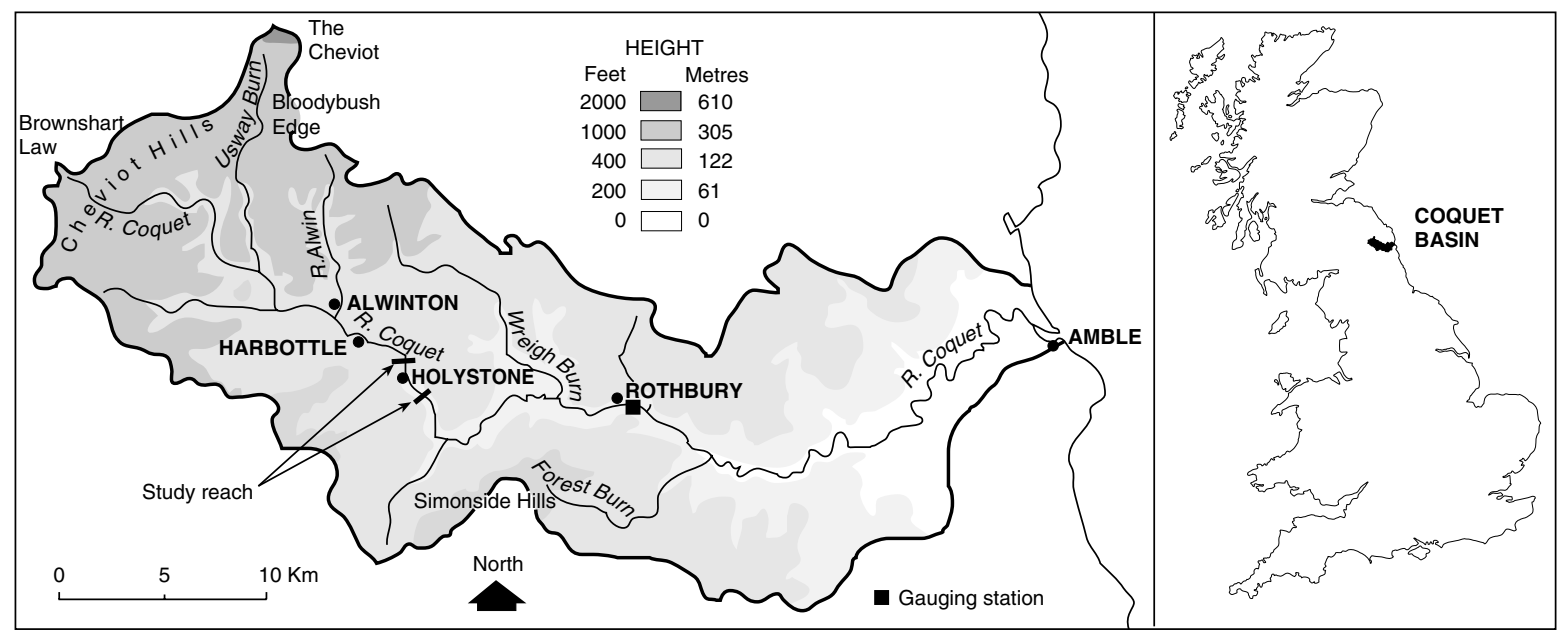

Figure 2. River Coquet catchment, Northumberland, UK, showing the location of the study reach

transformed to use the OSGB36 datum; this was carried out by the EA (Environment Agency, 1998). The data were then interpolated onto a $2 \mathrm{~m} \times 2 \mathrm{~m}$ grid.

Coincident with the LiDAR flight, channel cross-profiles were surveyed from monumented pegs on the riverbank using theodolite-EDM survey with a Total Station. This ground survey took one week around the date of the LiDAR acquisition flight, thus ensuring minimal discrepancy between LiDAR and ground survey cross-profiles due to morphological change. The ground survey measurements were made at every break of slope across the channel. The locations of the ground survey measurements were georeferenced by comparison with OS LandLine data. Of eighteen cross-sections used for sediment budgeting in the reach (Fuller et al., 2002), six cross-sections were selected for detailed comparison (Figure 3). These were selected on the basis 


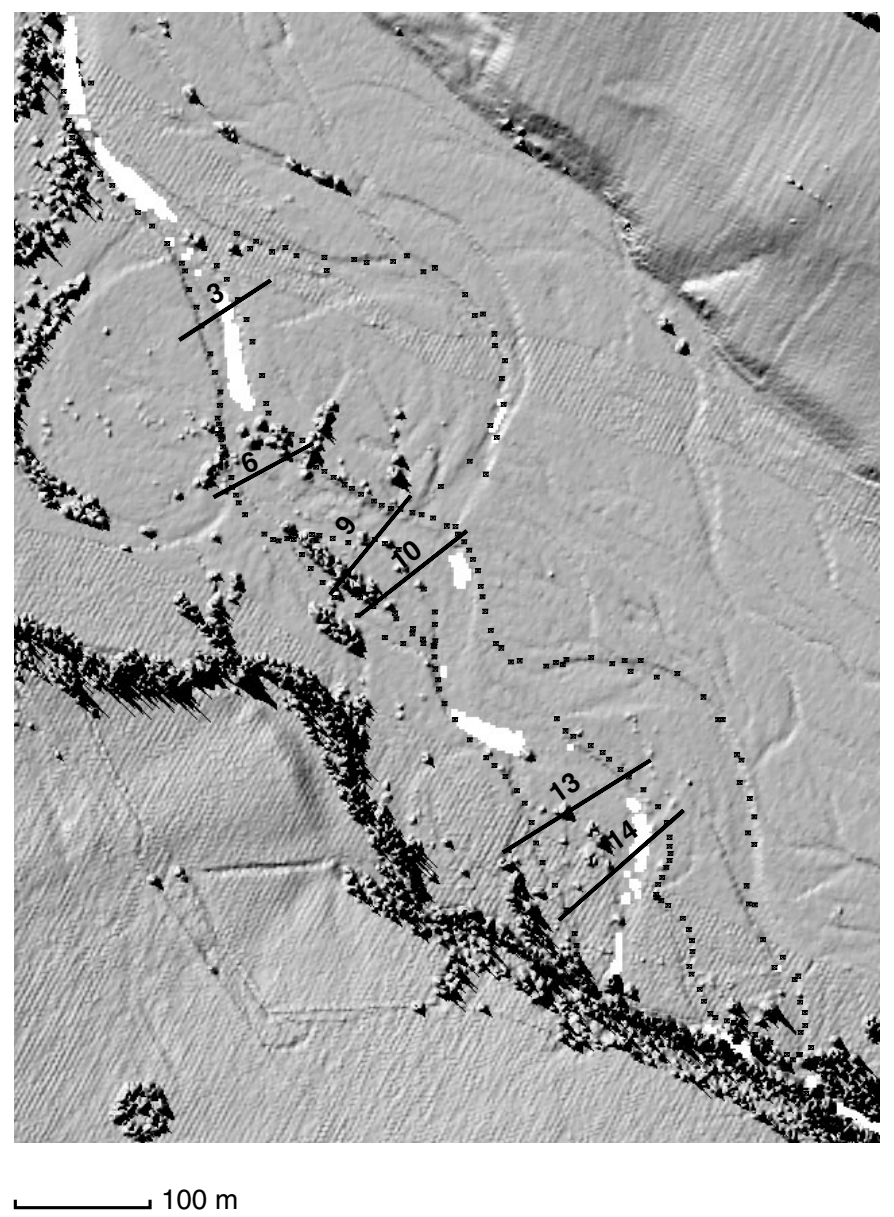

Figure 3. Location of cross-sections within the study reach. Cross-sections are numbered 3, 6, 9, 10, 13 and 14 run from northeast to southwest along the river channel; ground survey points denoting the base of bank are denoted by small black dots. Gaps in the LiDAR data set are denoted by white zones

that they covered the full range of channel morphology within the reach. Tying both the ground survey and LiDAR to a common planar coordinate system allowed accurate comparison of one with the other.

Georeferenced height values were calculated from the LiDAR data at $0.25 \mathrm{~m}$ intervals along the six crosssections using the surface profiling facilities available in Arc/INFO GIS. In total, this supplied 9152 estimates of elevation for the cross-sections. By comparison, there were only 551 measurements of elevation available from the ground survey. This engenders the problem that the measurements derived from the LiDAR surface were not taken at precisely the same positions along the cross-profile as those from the ground survey. To resolve this, the surface profiling facilities in Arc/INFO were used to generate interpolated values from the digital elevation model at a set of regularly spaced locations, within the mesh spacing of the model. Cubic splines (Press et al., 1989) were fitted to these measurements (a spline has the useful property that it passes through all the observed data points), and values were then interpolated from the spline function at positions corresponding to those along each cross-section at which ground survey elevations were obtained.

Elevations from the ground survey data were adjusted to the LiDAR elevation at the monumented peg for each cross-section, so that the first data point in all cross-sections had the same z-value as the LiDAR elevation for that specific location. This has the effect of removing the systematic bias component of the error associated with both the LiDAR measurement and the survey of the monumented peg. Assessing the magnitude and variation in the bias component requires further research however. 


\section{RESULTS AND DISCUSSION}

The measurement of channel cross-profiles using LiDAR and ground survey is compared in Figure 4. Several features are immediately apparent. At the time of survey, a number of mid-channel and lateral gravel bars along with isolated sections of the banks were colonized by stands of mature Alnus glutinosa. While much of this has disappeared since the 1998 survey as a result of a series of major flood events, this woody vegetation is evident on the cross-section LiDAR plots as 'spikes' in the elevation data. No spikes are seen in the ground survey data as vegetation was ignored. The zones of deeper water, evident in Figure 2 as white zones, are also replicated here as gaps in the LiDAR coverage in cross-sections 3 and 14. In addition, the nature of the single return measurement used here means deeper water is poorly represented in cross-sections 10 and 13. Elsewhere there is reasonable correspondence between the ground and LiDAR coverages, although no consistent pattern of superposition is apparent. The absolute differences in elevation between the LiDAR and ground survey profiles are shown in Figure 4. These differences are tabulated for the different surface characteristics along each profile (Table I).

It is evident that the mean difference figures exceed Fowler's (2000) estimation of precision $(15 \mathrm{~cm})$; this is due to discrepancies introduced by tall vegetation (trees) and deep water. When the figures are examined for the different surface characteristics, it is clear that the best correlation between LiDAR and ground survey is provided by the gravel bar surfaces. With the exception of cross-profile 6 , the figures for the gravel surfaces are consistent with Fowler's estimation of precision.

A one-way ANOVA test is appropriate to consider whether there is sufficient evidence for these differences. Tests were carried out on the whole data set as well as each of the cross-sections and the F-tests were seen to be significant at the 5 per cent level in all cases (Table II). However, these results only indicate that, for each test, at least one of the means is different from the rest. It is helpful to carry out post hoc tests to determine which of the three pairs of substrate means are significantly different. The results of a Scheffé test are shown in Table II for those substrate pairs which are significant at the 5 per cent level and some reasons for these differences are also summarized. (The Scheffé test permits post hoc multiple comparisons between a set of means; Scheffé, 1959.)

The LiDAR-generated cross-profiles are incomplete where there is deep water (e.g. cross-profile 3) and distorted where trees are present (e.g. cross-profiles 6,9,13 and 15). The absolute differences from the ground surface vary from $1.579 \mathrm{~m}$ (due to deep water) to $3.908 \mathrm{~m}$ (due to trees), where the degree of difference attributable to vegetation reflects the influence of first return data. Due to the distorting effects of vegetation, elevation values are difficult to delineate from base topography using a single return LiDAR survey. The LiDAR data provided by the EA trade off the frequency of measurement by the detector against pulse separation, a problem also encountered by Marks and Bates (2000). As Marks and Bates point out, the detector registers only the pulse returned from the terrain surface (vegetation or topography), and elimination of vegetation effects through height differencing of the first and last returns or the full return waveform (such as by Weltz et al., 1994) was therefore impossible. Some workers have made initial attempts to address this by gridding the data and applying a simple variance filter (Marks and Bates, 2000); however, this approach, while appearing a reasonable initial attempt to deal with this complex issue, inevitably leads to some loss of resolution (Marks and Bates, 2000). An alternative approach could be to use georeferenced aerial photography (if available) to distinguish and classify vegetation, permitting more vigorous elimination of LiDAR spikes in vegetated areas.

Aerial photographs have been used to estimate water depths in shallow gravel-bed rivers (e.g. Winterbottom and Gilvear, 1997; Gilvear et al., 1998), and although such an approach is limited in scope to rivers with shallow and relatively clear water, depth determination of up to one metre should be feasible with standard colour photography. However, in this reach of the River Coquet, pools frequently exceed this threshold depth. In attempting to overcome the same problem, Irish and Lillycrop (1999) recommend using multispectral laser imagery allowing subtraction of the difference between the reflection from the water surface of the shorter wavelengths from the longer wavelengths that can penetrate the water column. This approach permits measurement of the bed surface beneath deeper water provided that associated problems with turbulence and suspended sediment attenuating the penetration of light within a water column are not prohibitive. Such multispectral data were not, however, available for the River Coquet. In their absence, there is therefore a 

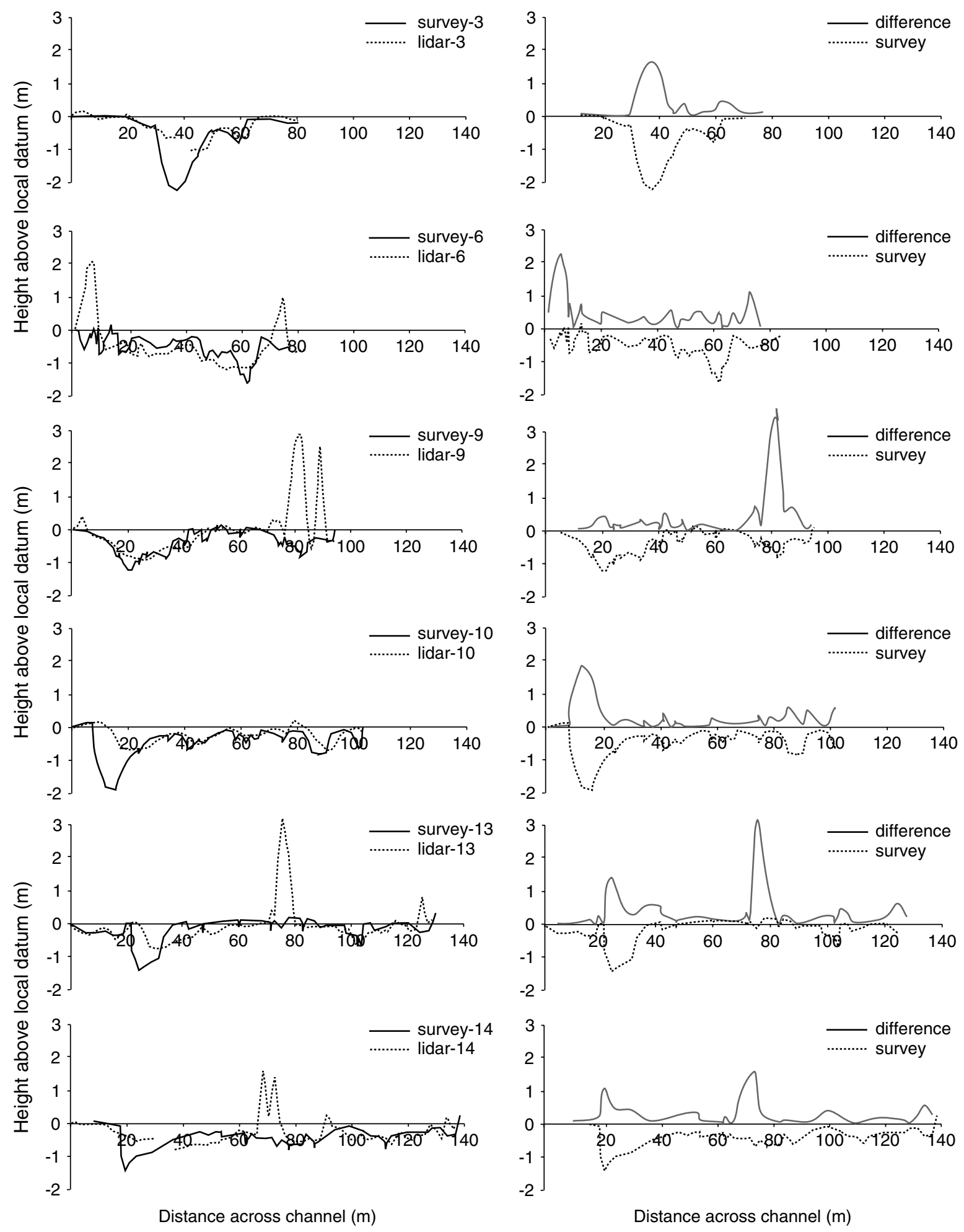

Figure 4. Comparison between LiDAR and ground survey for six cross-sections on the River Coquet. Absolute differences between LiDAR and ground survey profiles are also given 
Table I. Quantification of the absolute differences in metres between ground survey and LiDAR data

\begin{tabular}{ccccr}
\hline \multirow{2}{*}{ Cross-profile } & \multicolumn{3}{c}{ Absolute difference } \\
\cline { 2 - 4 } & Mean & Vegetated & Gravel & Wet \\
\hline 3 & $0 \cdot 305$ & $-^{*}$ & $0 \cdot 160$ & $0 \cdot 738$ \\
6 & $0 \cdot 546$ & $1 \cdot 210$ & $0 \cdot 328$ & $0 \cdot 259$ \\
9 & $0 \cdot 509$ & $1 \cdot 250$ & $0 \cdot 175$ & $0 \cdot 203$ \\
10 & $0 \cdot 363$ & 0.413 & $0 \cdot 171$ & $0 \cdot 732$ \\
13 & $0 \cdot 326$ & $0 \cdot 521$ & $0 \cdot 161$ & $0 \cdot 651$ \\
14 & $0 \cdot 291$ & 0.471 & $0 \cdot 161$ & $0 \cdot 557$
\end{tabular}

* No vegetation present on cross-profile 3.

Table II. Analysis of variance summary for the cross-profiles

\begin{tabular}{|c|c|c|c|c|}
\hline Cross-profile & ANOVA & $P$ & Significant pairs & Reason \\
\hline Alldata & $\mathrm{F}_{2,340}=38 \cdot 383$ & $0 \cdot 000$ & & \\
\hline 3 & $\mathrm{~F}_{2,24}=9 \cdot 167$ & $0 \cdot 001$ & Gravel - Wet & Deep water on profile \\
\hline 6 & $F_{2,62}=29 \cdot 149$ & $0 \cdot 000$ & $\begin{array}{l}\text { Vegetated - Gravel } \\
\text { Vegetated - Wet }\end{array}$ & $\begin{array}{l}\text { Trees present } \\
\text { Shallow water }\end{array}$ \\
\hline 9 & $\mathrm{~F}_{2,69}=16 \cdot 628$ & $0 \cdot 000$ & $\begin{array}{l}\text { Vegetated - Gravel } \\
\text { Vegetated - Wet }\end{array}$ & $\begin{array}{l}\text { Trees present } \\
\text { Shallow water }\end{array}$ \\
\hline 10 & $\mathrm{~F}_{2,72}=16 \cdot 223$ & $0 \cdot 000$ & Gravel - Wet & Deep water on profile \\
\hline 13 & $\mathrm{~F}_{2,50}=4.925$ & $0 \cdot 011$ & Gravel - Wet & Deep water on profile \\
\hline 14 & $\mathrm{~F}_{2,48}=7 \cdot 159$ & $0 \cdot 002$ & $\begin{array}{l}\text { Vegetated - Gravel } \\
\text { Gravel - Wet }\end{array}$ & $\begin{array}{l}\text { Trees present } \\
\text { Deep water on profile }\end{array}$ \\
\hline
\end{tabular}

virtue in adopting an integrated mapping approach by augmenting LiDAR using appropriately georeferenced ground survey.

\section{CONCLUSIONS}

If errors, particularly those from vegetation, can be reliably quantified, the results presented here suggest that LiDAR shows considerable potential for accurate mapping of gravel-bed river environments. The use of single return LiDAR data provides an exceptional opportunity for initial reconnaissance of extended reaches of channel systems. In the UK context, a multidisciplinary approach utilizing ground survey to augment data gaps increases the resolution of such channel mapping exercises. In environments where vegetation is less extensive, such as proglacial channel systems or braidplains, exclusive use of single return LiDAR may still offer an accurate method of acquiring high resolution data for bar surfaces above inundation, or where flow is sufficiently shallow that water depth does not distort the laser.

Ultimately, however, a scanning LiDAR that returns, as a minimum, first- and last-pulse information is required for many environmental applications including floodplain hydraulic modelling (Marks and Bates, 2000). First-pulse LiDAR measures the range to the first object encountered, such as the vegetated surface. Last-pulse LiDAR measures the range to the last object, represented in this study by unvegetated gravel bar surfaces. By acquiring such first- and last-pulse data simultaneously, both tree heights and the topography of the ground beneath can be addressed in a single pass (Optech, 2001).

\section{ACKNOWLEDGEMENTS}

The LiDAR dataset was kindly supplied by the National Centre for Environmental Data and Surveillance, Environment Agency, Bath. We gratefully acknowledge field assistance from Dr George Heritage, Dr David 
Passmore and Dr David Milan. We also thank Mr Brian Little and Mr Guy Renwick for granting access to the site. Comments from three referees are gratefully acknowledged.

\section{REFERENCES}

Bissonnette LR, Kunz G, WeissWrana K. 1997. Comparison of LiDAR and transmissometer measurements. Optical Engineering 36: $131-138$.

Brasington J, Rumsby BT, McVey RA. 2000. Monitoring and modelling morphological change in a braided gravel-bed river using high resolution GPS-based survey. Earth Surface Processes and Landforms 25: 973-990.

Brinkman RF, O’Neill C. 2000. LiDAR and photogrammetric mapping. The Military Engineer May-June.

Environment Agency. 1998. Local Environment Agency Plan: Cheviot and East Northumberland Action Plan. North East Region, Newcastle upon Tyne.

Ferguson RI, Werritty A. 1983. Bar development and channel changes in the gravelly River Feshie. In Modern and Ancient Fluvial Systems, Collinson JD, Lewin J (eds). International Association of Sedimentologists, Special Publication 6: $133-143$.

Fowler A. 2000. The lowdown on LiDAR. Earth Observation Magazine 7: 227.

Fuller IC, Passmore DG, Heritage GL, Large ARG, Milan DJ, Brewer PA. 2002. Annual sediment budgets in an unstable gravel bed river: the River Coquet, northern England. In: Sediment Flux to Basins: Causes, Controls and Consequences, Jones S, Frostick LE (eds). Geological Society, Special Publication 191; 115-131.

Gauldie RW, Sharma SK, Helsley CE. 1996. LiDAR applications to fisheries monitoring problems. Canadian Journal of Fisheries and Aquatic Sciences 53: 1459-1467.

Gilvear DJ, Waters TM, Milner AM. 1998. Image analysis of aerial photography to quantify the effect of gold placer mining on channel morphology, Interior Alaska. In Landform Monitoring, Modelling and Analysis, Lane SN, Richards KS, Chandler JH (eds). Wiley: Chichester; 195-216.

Innes JL, Koch B. 1998. Forest biodiversity and its assessment by remote sensing. Global Ecology and Biogeography Letters 7: $397-419$.

Irish JL, Lillycrop WJ. 1999. Scanning laser mapping of the coastal zone: the SHOALS system. ISPRS Journal of Photogrammetry and Remote Sensing 54: 123-129.

Irish JL, White TE. 1998. Coastal engineering applications of high-resolution LiDAR bathymetry. Coastal Engineering 35: $47-71$.

Jackson TJ, Ritchie JC, White J, Leschack L. 1988. Airborne laser profile data for measuring ephemeral gully erosion. Photogrammetric Engineering and Remote Sensing 54: 1181-1185.

Krabill W, Thomas R, Jasek K, Kuvinen K, Manizade S. 1995. Greenland ice thickness changes measured by laser altimetry. Geophysical Research Letters 22: 2341-2344.

Marks K, Bates P. 2000. Integration of high-resolution topographic data with floodplain flow models. Hydrological Processes 14: 2109-2122.

McHenry JR, Cooper CM, Ritchie JC. 1982. Sedimentation in Wolf Lake, Lower Yazoo river basin, Mississippi. Journal of Freshwater Ecology 1: $547-558$.

Optech. 2001. http://www.optech.on.ca/aboutlaser.htm.

Parson LE, Lillycrop WJ, Klein CJ, Ives RCP, Orlando SP. 1997. Use of LiDAR technology for collecting shallow water bathymetry of Florida Bay. Journal of Coastal Research 13: 1173-1180.

Press WH, Flannery BP, Teukolsky SA, Vetterling WT. 1989. Numerical Recipes in Pascal. Cambridge University Press: Cambridge.

Ritchie JC, Jackson TJ. 1989. Airborne laser measurements of the surface-topography of simulated concentrated flow gullies. Transactions of the ASAE 32: 645-648.

Ritchie JC, Everitt JH, Escobar DE, Jackson TJ, Davis MR. 1992. Airborne laser measurements of rangeland canopy cover and distribution. Journal of Range Management 45: 189-193.

Ritchie JC, Grissinger EH, Murphey EB, Garbrecht JD. 1994. Measuring channel and gully cross-sections with an airborne laser altimeter. Hydrological Processes 8: 237-243.

Ritchie JC, Humes KS, Weltz MA. 1995. Laser altimeter measurements at Walnut-Gulch watershed, Arizona. Journal of Soil and Water Conservation 50: 440-442.

Ritchie JC, Menentie M, Weltz MA. 1996. Measurements of land surface features using an airborne laser altimeter: the HAPEX-Sahel experiment. International Journal of Remote Sensing 17: 3705-3724.

Scheffé H. 1959. The Analysis of Variance. Wiley: New York.

Wadhams P. 1995. Arctic sea-ice extent and thickness. Philosophical Transactions of the Royal Society of London Series A 352: $301-319$.

Weltz MA, Ritchie JC, Fox HD. 1994. Comparison of laser and field-measurements of vegetation height and canopy cover. Water Resources Research 30: 1311-1319.

Westaway RM, Lane SN, Hicks DM. 2000. The development of an automated correction procedure for digital photogrammetry for the study of wide, shallow gravel-bed rivers. Earth Surface Processes and Landforms 25: 209-226.

Winterbottom SJ, Gilvear DJ. 1997. Quantification of channel bed morphology in gravel-bed rivers using airborne multispectral imagery and aerial photography. Regulated Rivers: Research \& Management 13: 489-499. 